\title{
Fake discourse in the space of mass media and media linguistic practices
}

\author{
Vita Maiba ${ }^{1 *}$ \\ ${ }^{1}$ Rostov State Transport University, 344038, Sq. Rostovskogo Strelkovogo Polka Narodnogo \\ Opolcheniya, 2, Rostov-on-Don, Russia
}

\begin{abstract}
The purpose of this study is determined by the importance and necessity of using and active disseminating false, fake reality in the space of media discourse and media linguistic practices to exert a manipulative influence on the audience. The paper shows that as a result of the medialinguistic practices analysis in the space of fake media reality there are opportunities to describe the variety of fake materials, as well as to detect a number of threats that demonstrate the facts of the destructive impact of fake discourse in the space of mass media in relation to consciousness and linguistic practices. The paper uses such methods and techniques for studying the structure of discourse and its strategies as content analysis; pragmatic analysis of speech and communicative acts; rhetorical and stylistic, genre, and other specifics of text structures (news, parliamentary debates, lectures, advertising texts, etc.) "within the framework of linguistic practices of communicative interaction.
\end{abstract}

\section{Introduction}

A retrospective analysis of the human civilization development shows that reliable facts (as a true phenomenon of reality) played an important part in communicative processes [1], being a certain measure of the truthfulness, expediency and effectiveness of phenomena, events, situations, communications and interactions.

However, the transformational changes in the traditional models of communicative interactions between the state, society [2] and the mass media served as a trigger that transformed the truth of fact and made it a special product of the media space. This product can be produced and released for public viewing by various actors. If earlier the truth of a fact was based on its reliability, then within the framework of modern reality, the truth of the produced product - the "fact" depends on the financial investments of the actors who produce it. All these reasons led to the development of a community of media consumers and the "fact" created by them, as well as to the emergence of the latest socio-political and linguistic phenomena that have changed the view of the truth to a fact. This paradigm shift requires scientific understanding and conceptualization.

Today, with a wide range of communication means in the conditions of total domination of various media channels and the need to obtain information without much effort and

\footnotetext{
* Corresponding author: vita.maiba@yandex.ru
} 
energy consumption, a person faces difficulties associated with obtaining necessary and reliable information; because the role, principles and functions of the reliability of the fact have changed: now there is a "post-truth era", which erases the boundaries between falsehood and truth". In the era of this "post-truth", the status of the truth of the fact decreases, and the false fact or, as they say in the conditions of modern mass consumption of information, "fake" comes to the fore.

\section{Materials and methods}

Since today the phenomena of "fake" and fake news are the subject of discourse research. It is necessary to understand that this kind of research involves the use of various analytical methods that are used considering the formulation of a specific task, the subject of research and other aspects. The scientific novelty is that the article analyzes media-linguistic practices in the space of fake media reality; the threats to the psycho-emotional and cognitive levels of human consciousness, as well as the ethical and spiritual and moral foundations of social consciousness are considered.

As a result of the analysis of media linguistic practices in the space of fake media reality, varieties of fake materials are described, and several threats have been discovered that demonstrate the facts of the destructive impact of fake discourse in the mass media space in relation to consciousness and linguistic practices.

\section{Results}

Even though the definitions of "fake" and "fake news" have practically penetrated the socio-political reality and the media space, the terminological definition of fake has not been presented yet in the explanatory official dictionaries of the Russian language, linguistics, sociology and political science.

Although this definition is not indicated in explanatory dictionaries, this term and its concept is found on the Internet. In Wiktionary, the term "fake" means a slang neologism "something mendacious, deceitful, untrue, fake and misleading" [3]. According to the Oxford Dictionary, the etymology of the lekseme "fake" is semantically related to the verbs "clean up", "sweep" and contains the idea of deception, misleading [4]. While in the dictionary of computer terms the concept "fake" is clearly defined as a forgery, deception. It is also worth noting that the term "fake" within the information space is usually used to denote modified photos and videos (special graphic editors are used for this): "Fake (English fake / fek /) - fake, falsification, deception; as a rule, it is used to identify distorted materials) with the help of special editor programs of original digital photo or video files" [5].

It is necessary to understand whether fake discourse in the media space is a threat to linguistic practices and the world order in general, in this regard, it is necessary to focus in detail on the interpretation of this concept, because, as the analysis of scientific literature in the framework of interdisciplinary research has shown, the term "fake" is interpreted extremely widely and multifaceted.

Most often, at present, a fake is called a photo and video production that infiltrates the mass media after processing in specialized programs, for example, Photoshop and other photo and video editors. Fakes are also called pages in various social networks that are created by a fictional character. If we take the mass media, then there are fabricated texts in news feeds filled with implausible information. In this regard, M.Yu. Ershov stresses that currently various simulacrums may be called fake, the aim of which is to decrease the reputation of a social institution or a certain individual [6]. 
The problem of fake and fake news in mass media is actively addressed by researchers from the field of linguistics, journalism, politics, media linguistics. Theoretical and methodological reflection of media linguists, whose "research practice cannot remain indifferent to the research impulses emanating from its environment, and be closed in a narrowly understood linguistic tradition" [7] defines the methods of cognition in the form of various discourses, fake discourses, media-linguistic practices.

In the works of O.S. Issers case as illustrative examples of lexical markers, determinants, pointing to deliberate manipulative influence in advertising, the author gives as an example such phrases as "You will be amazed at this!" "This species is threatened with extinction"; "Scientists have made a world-class discovery"; "Something terrible has happened" [8].

The study of fake discourse in media reality can be traced in the work of L.I. Grishaeva, who points out that one of the obvious reasons for the appearance of fake news, fake pages and photos is the uncertainty the society you live in. In a changed social reality, permeated with various kinds of risks and uncertainties, the ways of comprehending reality that existed before do not work. In this regard, fakes begin to penetrate a person's life [9].

N.S. Kotov and S.S. Dukyan consider phenomenon "fakes" in political discourse of "post-truth", saying that it is now gaining momentum transition «from the society of the facts to the society of data, when the status of knowledge and numbers in public life is changing, and the truth itself is rejected» [10].

N.N. Kashkarova and E.S. Boyko come to a reasonable conclusion that the main feature of fake discourse is the environment in which fakes exist. In the media space, you can come across various fake news, from advertising a product, to provocation in the field of politics. Here we see the process of active mimicry of fakes and true messages [11].

Media-linguistic practices, expressed in the media text as a unit of media discourse, are characterized as a system of verbal signs. Such signs can be of different levels - linguistic, graphic, sound, visual. The combination of these characters is selected in accordance with the information transmission channel. In the study fake discourse is a collection of various kinds of processes and products of speech activity that mislead listeners and readers.

Analysis of media linguistic practices in the space of fake media reality shows us the following types of fake materials:

-within the social network Facebook, fake accounts and fake profiles are created (due to anonymity and a simple registration procedure in the media space), to represent a profile on the social network of a fictitious person or a person who exists in reality, but created by another person ;

-pages of fake sites are created on social networks with distorted or completely false information about facts, events and phenomena for various unfavorable purposes, for example, for the purposes of striving for cheap popularity, personal data theft, manipulative influence, striving for profit. Moreover, profit, for example, can be calculated not only in monetary terms, but also in socio-political dividends, which include an increase in ratings, initiation of a discourse on the topic proposed by the author.

-in a series of news reports in the mass media, an innovative news technique is used, built according to a certain scheme, and dedicated to specific public figures. This is a technique in which a part resembling the truth is laid out in the title, but in the process of following the link, information appears that carries the idea of deception, misleading or, jokes at best [8].

-fake video and sound recordings are edited and actively placed in the mass media, through which the memories of the target audience are manipulated.

-in turn, fabricated photo, video, and sound recordings can contribute to the formation of the so-called. false memories associated with a false or distorted perception of those events and facts that may never happened in reality [12]. 
-as part of the functioning of online stores, ratings of store goods are formed, which appear because of left fake reviews in relation to a particular product, which are misleading and undermine the confidence of buyers of goods in online stores [13].

Semantically, the term "fake" is associated with other synonymous terms, such as, for example, "information hoax", "disinformation", "media fake".

The term "media fake" is used by O.S. Issers. The author applies this category in relation to fakes in the media space, the main purpose of which is the mystification of information. The author also emphasizes that fakes "cover various cases of hoaxes and forgeries" (Issers, 2015). That is, the range of media fakes goes beyond misleading the reader.

In the opinion of the researchers K.A. Olkhovsky and P.E. Suslonov the concept of "fake" in information discourse represents information hoax or disinformation that is spread in the media space [14].

Thus, the analyzed material allows us to define what "fake media reality" is. Fake media reality is a phenomenon, which forms the media linguistic environment, where real facts are replaced by imaginary images, which in their turn have all the properties of the true facts and can affect the recipient for the purpose of every kind of manipulative influence. Thus, despite the fact that fakes are phenomena of media-linguistic reality, they can have a serious impact on real life [15]; [16].

Revealing the topic of fake discourse in the mass media space, Russian researchers dealing with fakes in the media space S. S. Raspopova and E.N. Bogdan identified a typology of information hoax messages, and identified the following types and information products:

-scientific hoax (in the focus of attention sensational discoveries in various scientific fields are considered);

-political hoax (political figures speeches can be included here that raise doubt among journalists and the public about the authenticity of these messages);

-hoaxing documents (fake documents are analyzed here that are spreading on the Internet or social networks as official ones);

-mockumentary documentaries (pseudo-documentary films can be included);

-journalistic hoax (false reports, which are created by journalists and which deals with the absurd situation).

Since almost all mass media are in a competitive environment with certain principles of mass-media selection and entering the competition those channels of mass-media have more chances to win, that use "fake web" news, in order to please the politicians ... At the same time, N.S. Kotov and S.S. Dukyan describe truthfully today's reality: "the more actively "fakes" are included in the political discourse instead of true facts, the more successful and reliable the statements and approvals promoted by politicians seem to be" $[10]$.

\section{Discussion}

So, back to the question, is fake discourse in the mass media a threat to linguistic practices, the minds of the manipulated audience, and the world order as a whole?

Our analysis revealed a number of threats that demonstrate the facts of the destructive impact of fake discourse in the media space in relation to consciousness and linguistic practices. According to the apt expression of the researcher Yu.M. Ershov, fake information in the form of viral videos and photos is a product that has appeared in the modern world and is spreading with great speed among the public like a virus. [6].

Since fake discourse in the mass media is gaining momentum, this influences the emergence of a communicative culture, which researchers call the post-truth. The 
mechanism of work of the post-truth communicative culture works through influencing the consciousness of people by referring to emotions and feelings, the factual details are left aside. In this case, according to the fair point of N.N. Kashkarova and E.S. Boyko, "an evolutionary mechanism is triggered, which is typical for the discourse of "a new sensitivity", when the emotions" of fear, panic, surprise, and feelings "dominate the mind" [11].

Secondly, repetition, reproduction or quotation of fake information (including even its contextual framework of refutation, challenge), one way or another, causes serious damage to verbal communication: "the more often the reader hears about this, the more familiar the event is inclined to believe in it" [6]. As A.V. Nikolaeva inderlines, "emotion in modern media is becoming more important than fact, and opinion is more important than reliability" [17]. Thirdly, because of the impact on the consciousness of extreme emotions, misinformation and discrediting, habitual value orientations are substituted and public opinion changes [18], and this change is enhanced by the inclusion of pseudo-social polls in the media discourse. Changes in public opinion, in its turn, contribute to the formation of new models of media linguistic practices. In the work of A.V. Nikolaeva noted that media linguistic practices have such characteristics as a colloquial and expressive syntax [19], "the absence of reasonable proportions in the material between the denotative and emotive parts", as well as the imbalance between the norm/ abnormality "at all levels of content (thematic, meaningful, lexical, syntactic) [17].

Fourth, in modern media discourse, including political, is becoming more and more obvious linguistic manipulation of the basic values of modern society [20], because the main "function of fake information is manipulative, acting on the mass consciousness [21].The purpose of manipulators and falsifiers of information is fill people's minds with distorted reality. They push the real facts out of consciousness. The individual, whose mind is engulfed by such news, loses immunity to misleading facts. Is not this an evidence of a threat to the ethical and spiritual and moral foundations of human consciousness?

As Yu. M. Ershov emphasizes, fake discourse and news in the space of the media negatively affect the consciousness of the population even then, when the forgery is exposed. Thus, the side effects of fake are much heavier than its direct impact» in relation to consciousness and linguistic practices [6].

It is necessary to consider that fake discourse as a product of media linguistic practices is endowed with a specific set of characterological features, identical, according to N.N. Kashkarova and E.S. Boyko, "functional and structural-semantic to the features of tough news" [21]. At the same time, fake news in the media space allows the recipient to conduct a discursive and linguistic-stylistic analysis of news messages and evaluate the news from the perspective of "false - truth".

\section{Conclusion}

All the above can draw some important conclusions that fake discourse in the space of the media and the media linguistic practices is becoming a major social, political, communicative and linguistic problem. Its solution depends on many factors, starting from legislative measures of policy and culture, checking facts for their truthfulness at the state level, ending with the formation of an active citizenship of members civil society. In the modern world information plays an important part both in the life of individuals, groups and communities, that is why great attention should be paid to the authenticity of the information so that society does not plunge into the abyss of fake "post-truth". It is for this reason that it is important to develop a really acting fake detection mechanism in mass media products. 


\section{References}

1. N. Kh Gafiatulina, Ya. V. Artamonova, (SFedU, Rostov-on-Don, Taganrog, 2019)

2. I. E. Ponomarev, N. K. Gafiatulina, E. I. Zritineva, et al., International Journal of Applied Exercise Physiology, 8(2.1), 250-257 (2019), doi.10.30472/ijaep.v8i2.1.566.

3. Wiktionary (n.d.), Retrieved from: https://ru.wiktionary.org/wiki/fake.

4. The Oxford English Dictionary (1989), Retrieved from: https://archive.org/details/oxfordenglishdic0017unse/ page/n7/mode/2up.

5. Dictionary of computer terms (n.d.), Retrieved from: https://computer.slovaronline.com/ 1187-FEYK.

6. Yu. M Ershov, Bulletin of the Tomsk State University, 52, 245-256 (2018), doi.10.17223/19986645/52/15.

7. St. Gaida, (Media). Media Linguistics, 3(9), 15-23 (2015)

8. O. S. Issers, New Media in Russia: Studies of Language and Communication Processes (2015), Retrieved from: https://cyberleninka.ru/article/n/mediafeyki-mezhdu-pravdoyi-mistifikatsiey.

9. L. I. Grishaeva, Political Linguistics, 2 (2017)

10. N. N. Kotova, S.S. Dukyan, State and Municipal Management, 2, 130-135 (2018), doi.10.22394/2079-1690-2018-1-2-130-135

11. N. N. Kashkarova, E.S. Boyko, Political Linguistics, 2(80), 77-82 (2020), doi.10.26170/p120-02-08.

12. M. Montgomery, Journal of Language and Politics, 16, 619-639 (2017), doi.https://doi.org/10.1075/jlp.17023.mon.

13. G. Fauconnier, M. Turner, Basic Books, 440 (2002), Retrieved from: https:/tecfa.unige.ch/tecfa/maltt/cofor-1/textes/Fauconnier-Turner03.pdf.

14. K. A. Olkhovsky, P. E. Suslonov, Innovative potential of youth: social, environmental and economic sustainability, 199-202 (2018), Retrieved from: http://hdl.handle.net/10995/68458.

15. N. Kh. Gafiatulina, D. M. Brusentseva, Humanities, Socio-Economic and Social Sciences, 6-7, 36-40 (2017).

16. V. V.Maiba, M. A. Polivina, O. I. Shkuropiy. Humanities, Socio-Economic and Social Sciences, 12(1), 71-74 (2020).

17. A. V. Nikolaeva, Verkhnevolzhskiy Philological Bulletin, 3(18), 55-59 (2019), doi.10.24411/2499-9679-2019-10482.

18. N. Kh. Gafiatulina, A. A. Vakulyuk, E. E. Fedorenko, National Health, 3(4),103-109 (2016), doi.10.15405/epsbs(2357-1330).2019.12.4.

19. A. V. Nikolaeva, Russian Speech, 3, 43-47 (2018), doi.10.7868/S0131611718030073.

20. V. V. Maiba, Modern Scientist, 4, 210-215 (2020), doi.10.25136/24098698.2018.2.25880.

21. F. G. Fatkullina, E. M. Zaripova, World of Science, Culture, Education, 3(82), 387-388 (2020), doi.10.24411/1991-5497-2020-00587. 